\title{
Music Distraction Effectiveness in Dental Anxiety and Treatment Adherence in 6-Year-Old Children: A Randomized Clinical Trial
}

\author{
Efectividad de la Distracción Musical Sobre la Ansiedad Dental y Adherencia \\ a Tratamiento en Niños de 6 Años: Ensayo Clínico Aleatorizado
}

Gonzalo A. Rojas-Alcayaga1; Karen Alfaro², Matías Ríos-Erazo¹, Andrea C. Herrera1 \& Pilar Barahona²

ROJAS-ALCAYAGA, G. A.; ALFARO, K.; Ríos-eRAZO, M.; HERRERA, A. C. \& BARAHONA, P. Music distraction effectiveness in dental anxiety and treatment adherence in 6-year-old children: A randomized clinical trial. Int. J. Odontostomat., 12(1):35-42, 2018.

ABSTRACT: Dental anxiety can be a barrier to following healthy behaviours. Musical distraction is an effective strategy to reduce dental anxiety and improve treatment adherence. The aim was to determine the effect of musical distraction on dental anxiety and treatment adherence in 6-year-old children. Multicenter randomized control trial with 176 children who were allocated into two parallel groups. One group received usual dental care ( $\mathrm{N} 88$ ), and the other was exposed to musical distraction during usual dental care (N 88). The primary outcome was dental anxiety and secondary was oral health status and oral health care behaviours. Both were assessed at baseline, discharged and six-month follow-up. Mid/high dental anxiety was exhibited by $16.1 \%$ of the children. Musical distraction had no effect on dental anxiety levels in the experimental compared with the control group at any of the time points assessed. The size effect was 0.35 and 0.15 (Cliff's Delta) for baseline-discharge and 0.57 and 0.35 for baseline-six month. Only $47.7 \%$ of the sample attended at 6-month follow-up. Dental anxiety is not prevalent in the sample and is not beneficially reduced by musical distraction. The educational actions of the dental care programme are not sufficient to attain permanent long-term changes in oral health behaviour.

KEY WORDS: musical distraction, dental anxiety, dental care for children, patient compliance.

\section{INTRODUCTION}

Caries is the most common chronic disease in childhood and is therefore of great importance in Public Health (Sheiham, 2005). The caries prevalence in Chile is 17 per cent in two-year-old children, 50 per cent in four-year-old children, and 70 per cent in six-year-old children (MINSAL, 2015). The severity of dental caries measured by the decayed, extracted, filled teeth index (def-t) is 0.5 in two-year-old children, 2.3 in four-yearolds, and 3.7 in six-year-olds (MINSAL, 2015).

Most likely, one aspect that effects the high damage caused by caries in children is the difficulty of adhering to the instructions delivered by the oral health team. Adherence to treatment (AT) in children is influenced by many factors, such as age, parental education level, maternal perceptions about dental care, socioeconomic status and dental anxiety (DA) (Edelstein, 2002; Edelstein \& Chinn, 2009; Goettems et al., 2012;).

Broberg \& Klingberg define DA as a state of fear that something terrible will happen in relation to dental treatment or certain aspects of dental treatment (Sanikop et al., 2011). Children classified with DA have significantly more cavities than children who are considered relaxed, with values of 2.58 and 1.12 def-t, respectively (Milsom et al., 2003). These patients also go to the dentist less often as a result of this fear, waiting longer before seeking dental care, thus affecting their oral health (Eitner et al., 2006; Armfield et al., 2007).

${ }^{1}$ Behavioral Sciences Area, Institute for Research in Dental Science, Dental School, Universidad de Chile. Santiago, Chile.

${ }^{2}$ Dental School. Universidad de Chile. Santiago, Chile.

This research project was funded by the National Fund for Health Research (FONIS, for its acronym in Spanish) under the National Commission for Scientific and Technological Research (CONICYT) and the Ministry of Health of Chile (MINSAL, its Spanish acronym). Project code: SA11I2025. 
The prevalence of this phenomenon ranged from 6.3 per cent of the children in India to 18 per cent in Brazil (Chhabra et al., 2012; de Carvalho et al., 2013). There are several articles that studied the use of cognitive-behavioural interventions in the treatment of DA. One such technique that yielded good results was musical distraction (MD), defined as the use of music as an adjuvant therapy in the treatment of behavioral disorders. MD leads the child to focus on the audio by listening in order to avoid the perception of aversive stimuli, such as the micromotor or turbine, thereby reducing levels of DA (Marwah et al., 2005). This technique is effective, especially in patients with moderate anxiety (Lahmann et al., 2008). However, there is great heterogeneity between studies, showing much variability in clinical scenarios, forms of application, types of music and method of delivery. Based on these studies, it is suggested that MD be used with other distraction techniques for best results (Klassen et al., 2008).

With this background, it is necessary to consider whether MD significantly improves the oral health performance of an anxious child and, in turn, whether reducing the levels of DA encourages the child to be more willing to undergo dental treatment and education delivered by the oral health team. This could have a positive effect on adherence and therefore an impact on the future oral health status of the child. If this were so, one could expand the use of this technique because of its ease of implementation and low cost compared with other strategies.

The aim of this study was to determine the effect of musical distraction on dental anxiety and adherence to dental treatment in 6-year-old children who participated in a public oral health programme. We hypothesized that the experimental group would decrease the dental anxiety levels at the end of the interventions and at the follow-up.

\section{MATERIAL AND METHOD}

As this study involved human research, the ethical implications for its development were conducted in accordance with ethical principles of the World Medical Association Declaration of Helsinki. Although no risks were involved for the children, the study did not imply a significant benefit. All children received routine dental care under the principles of empathetic interaction. The dental treatment plan remained unchanged at the technical-professional level during the study period.
Caregivers' informed consent and children's assent to participate were solicited. These forms were signed by the caregivers of the children and by the researchers. This study was approved by the ethics committee of the School of Dentistry, Universidad de Chile.

Study Design. The participants were recruited by referral from the population receiving usual dental care at Recreo, Alfonso Leng and Bellavista Family Health Center (Primary Health Care Centers) from different municipalities of Santiago, Chile. The sample included a total of 176 children of both sexes with an age range from 6 years to 6 years 11 months and 30 days, who required dental care and were beneficiaries of the public oral health program. A sample size of 130 was calculated according to a comparison of dependent means, an estimated 0.05 alpha error, statistical power of 0.95 , and a medium (0.5) size effect. This was considered based on previous results of music distraction intervention in children with dental anxiety (Marwah et al.). The G-power program was used for this propose. The inclusion criteria were as follows: Chilean nationality; 6 years of age; recipients of the public oral health program; and accompaniment by a legal guardian with information regarding their previous dental care. The exclusion criteria included the following: Children who had cognitive deficits, neurological disorders, generalized anxiety disorder (identified in the medical record or reported by the caregiver), or chronic systemic diseases and children requiring more complex psychological interventions or dental treatment under general anaesthesia due to dental phobia.

A parallel randomized not blinding controlled trial was conducted (Fig. 1). The primary outcome assessed was the child's dental anxiety and secondary outcomes were oral health status and oral health care behaviours. All of the assessments were made at the time of admission to the public oral health program (baseline), at the end of the treatment and six-months later.

A block randomization was made by the Random Allocation program in both groups with an allocation ratio $1: 1$. For every block of twenty participants, ten were allocated to each group. The allocation sequence was generated by the first author (GR) and the enrolment and participants assignment was performed by the researchers (GR, MR, $A H, K A)$. The intervention was administered by unblinded dentists. The experimental group received usual dental care that included an education session in association with musical distraction. The music was delivered by earphones through a device 
(mp3) where the child could choose the type of music. The control group received usual dental care that included an education session.

Outcome measures. Demographic information, dental anxiety self-report scale, oral behaviors questionnaire and saliva samples were taken prior to dental care outside of the dental office. Inside the dental office, six calibrated dentists recorded clinical indicators and the behavior of the patient in the dental chair using the Frankl Scale. If DA was high (dental phobia), the treatment plan involved more than 6 visits or the child required special dental care, the children were excluded from the study. All of the measurements were taken again at the end of the visit, as well as six months after the treatment.

To measure dental anxiety, the Facial Image Scale (FIS) and Frankl behavioral rate scale (FBRS) were applied. The FIS scale was developed by Buchanan \& Niven (2002) can be applied to 3- to 18-year-olds. It consists of a row of five faces ranging from great happiness to sadness. The child was asked to indicate which face was most related to how they felt at the time by a member of the research team prior to each dental session.

The FBRS (Frankl et al., 1962) assesses the patient behaviour in the dental chair at the time of treatment. The dentist evaluates the patient behaviour from "definitely negative" to "definitely positive." This scale was used at the end of each session by dentists. Both the FIS and FBRS were validated by the Delphi technique and expert consensus.

To assess the oral health of the patient, the treating dentists determined the def-t index and simplified oral hygiene index (OHI-S), created by Green and Vermillion in 1960. The def-t index and OHI-S interobserver agreement was evaluated through a clinical examination of children. The indices were recorded by the dentist in the dental chair using a dental mirror and probe at the time of the entrance of the patient into the public oral health program.

In addition, unstimulated saliva samples were collected in test tubes during 5 minutes by researchers for microbiological analysis of the Streptococcus mutans score in the microbiology laboratory of the School of Dentistry, University of Chile. The samples were cultured in yeast-extract cysteine sucrose bacitracin for $48 \mathrm{~h}$ at 37 degrede. The S. mutans score was determined using a Zeiss stereomicroscope (Stemi 2000C, Zeiss, Edmund Optics Inc., Barrington, New Jersey, USA). The number of S. mutans considered indicative of high-risk caries was 105 per $\mathrm{ml}$ of saliva.

The def-t index for primary teeth is an adaptation of the decayed, missing, filled teeth (DMFT) index proposed by Gruebbel. The def-t index records the experience of past and present caries, teeth indicated for extraction, and filled teeth, considering all 20 primary teeth. It corresponds to an easily performed traditional epidemiological index, which is recorded by the dentist in the first clinical session (Piovano et al., 2010).

Statistical methods. For the analysis of data, a descriptive statistics was used to evaluate the variables. To check the baseline, discharge and follow up for prepost intervention for dental anxiety scores (FIS and Frankl Scales), Friedman test was used. To determine the intervention efficacy between control and experimental group in primary outcome (dental anxiety), U-Mann Whitney test was used. To determine the intervention efficacy between control and experimental group in secondary outcomes (oral health, assessed through def$\mathrm{t}$ index, OHI-S and S. mutans; and oral behavior questionnaire), U-Mann Whitney test was used. For correlation between FIS Scale and Frankl Scale, a Spearman test was used. A P-value less than 0.05 was considered statistically significant. All data were processed by SPSS software (12.0, SPSS Inc., Chicago III, USA).

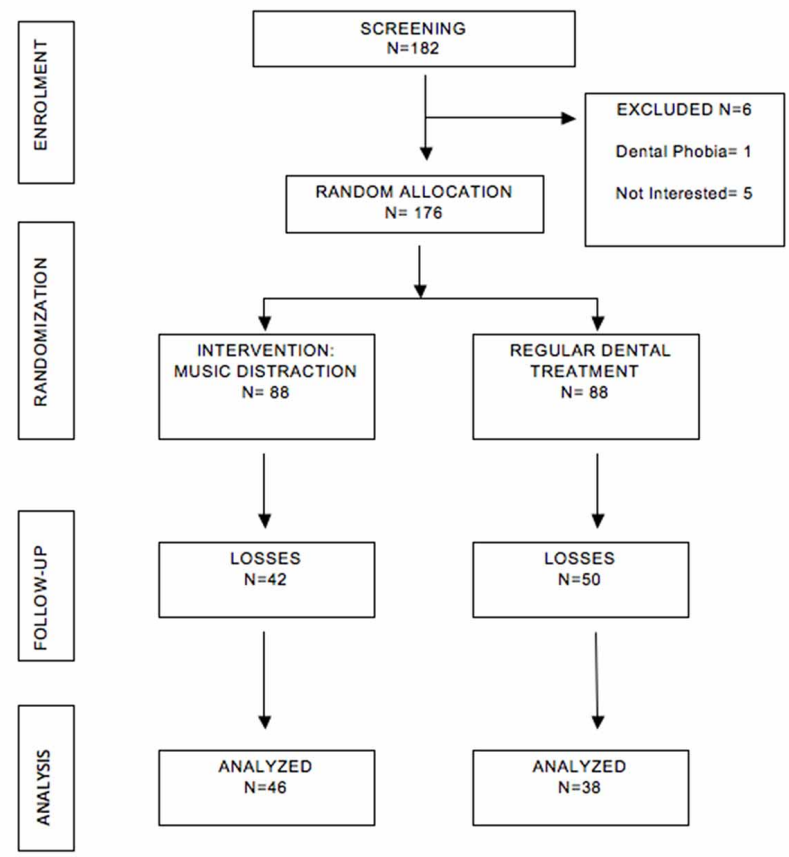

Fig. 1. Flow Cart. 


\section{RESULTS}

Characteristics of participants. The initial sample comprised 176 children admitted for dental treatment as part of a public oral health program for 6-year-old children and was randomized 88 children to each group. Of these, 66 children did not complete their dental treatment, and therefore were not discharged, 26 were not present at the six-month follow-up because they did not attend to the dental control, and it was not possible to contact them by phone. Therefore, 84 children were analyzed (Table I). The recruitment started in April 2012 and finished in December 2012. The follow-up lasted 6 months and finished in July 2013.

Oral Health Outcomes. At the time of entrance, 80.7 $\%$ of children showed a low risk of caries as assessed by S. mutans score. However, they showed an average of 3.3 in the dmf-t, which can be interpreted as a significant level of severity (Table II). In addition, 50 $\%$ of the children had an optimum $\mathrm{OHI}$ level and only $19.2 \%$ had a poor OHI level. At the time of discharge, the $\mathrm{OHI}$ average significantly decreased, but at the six-month follow-up, there was an important increase. Caries risk, as assessed by $S$. mutans score and the decay component of dmf-t, decreased significantly at the discharge time point, but at the six-month followup, there was an increase in decay tooth. These changes are consistent with the oral health behaviours recorded, which showed improvement at discharge but significant decline at the six-month follow-up (Table II).

Child Dental Anxiety. Most of the children showed low levels of dental anxiety at the several evaluation time points, and no differences were observed throughout the assessment sessions (Friedman, $p=0.16)$.

Moreover, no difference was observed in the FIS score between the experimental and control groups at the admission, discharge and six-month. (MannWhitney, $p=0.26 ; p=0.94 ; p=0.63$ and $p=0.15$, respectively). The size effect for experimental group at baseline-discharge was 0.35 (Cliff's Delta) and 0.57 (Cliff's Delta) at baseline-six month. When dental anxiety was assessed by Frankl scale, the assessment

Tabla I. Sample Characteristics.

\begin{tabular}{lcccccc}
\hline & \multicolumn{2}{c}{ Experimental } & \multicolumn{2}{c}{ Control } & \multicolumn{2}{c}{ Total } \\
Sex & Number & $\%$ & Number & $\%$ & Number & $\%$ \\
\hline Men & 48 & 54.5 & 49 & 55.7 & 97 & 55.1 \\
Women & 40 & 45.5 & 39 & 44.3 & 79 & 44.9 \\
Total & 88 & 100 & 88 & 100 & 176 & 100 \\
Caregiver & & & & & & \\
$\quad$ Mother & 66 & 75.0 & 67 & 76.1 & 133 & 75.6 \\
Grandparents & 12 & 13.6 & 7 & 8.0 & 19 & 10.8 \\
Father & 8 & 9.1 & 10 & 11.4 & 18 & 10.2 \\
Others & 2 & 2.3 & 4 & 4.5 & 6 & 1.1 \\
$\quad$ Total & 88 & 100 & 88 & 100 & 176 & 100 \\
Health Center & & & & & & \\
Recreo & 66 & 75.0 & 67 & 76.1 & 133 & 75.6 \\
Leng & 16 & 18.2 & 15 & 17.1 & 31 & 17.6 \\
Bellavista & 6 & 6.8 & 6 & 6.8 & 12 & 6.8 \\
Total & 88 & 100 & 88 & 100 & 176 & 100 \\
Chief Complaints & & & & & & \\
$\quad$ Preventive Care & 49 & 73.0 & 47 & 66.2 & 96 & 69.6 \\
Dental Treatment & 8 & 12.0 & 18 & 25.3 & 26 & 18.8 \\
Dental Emergency & 10 & 15.0 & 6 & 8.5 & 16 & 11.6 \\
Total & 67 & 100 & 71 & 100 & 138 & 100 \\
\hline
\end{tabular}


of behavior in the dental chair showed that the majority of children (93\%) displayed favorable behaviour with significant differences between baseline, discharged and six-month (Friedman, $\mathrm{p}=0.038$ ). The size effect for experimental group at baseline-discharge was 0.15 (Cliff's Delta) and 0.35 (Cliff's Delta) at baseline-six month.
FIS and Frankl scale results show a significant correlation with each other (Rho Spearman $=-0.24$, $\mathrm{p}=0.002$ ). These data show that MD-based intervention had no effect on dental anxiety records in both the selfreported (FIS) and the observed behaviour (Frankl), and neither on clinical records, S. mutans count nor oral health behaviours.

Table II. FIS and Frankl score at different times of assessment sessions.

\begin{tabular}{|c|c|c|c|c|c|c|c|}
\hline \multirow{2}{*}{ FIS Score } & & \multicolumn{2}{|c|}{ Admission } & \multicolumn{2}{|c|}{ Discharge } & \multicolumn{2}{|c|}{ Six-month } \\
\hline & & Mean & SD & \multicolumn{2}{|r|}{ SD } & \multicolumn{2}{|c|}{ SD } \\
\hline \multirow{7}{*}{ FrankI Scor } & Experimental & 1.57 & 0.99 & 1.44 & 0.78 & 1.38 & 0.76 \\
\hline & Control & 1.67 & 0.95 & 1.33 & 0.51 & 1.40 & 0.94 \\
\hline & $p$ value & \multicolumn{2}{|c|}{0.26} & \multicolumn{2}{|c|}{0.94} & \multicolumn{2}{|c|}{0.63} \\
\hline & & & & & & & \\
\hline & Experimental & 3.1 & 0.061 & 3.4 & 0.06 & 3.3 & 0.07 \\
\hline & Control & 3.2 & 0.056 & 3.4 & 0.07 & 3.2 & 0.09 \\
\hline & $p$ value & \multicolumn{2}{|c|}{0.76} & \multicolumn{2}{|c|}{0.53} & \multicolumn{2}{|c|}{0.34} \\
\hline
\end{tabular}

\section{DISCUSSION}

The aim of this study was to investigate the longterm effect of musical distraction on dental anxiety and adherence to treatment in an oral health programme for six-year-old children.

The results showed that musical distraction had no effect on the experience of dental anxiety among children who entered the oral health programme. However, this result could be explained by the low frequency of dental anxiety in the sample. In our study, and contrary to the expectations, the proportion of children with moderate or severe dental anxiety was low (16.1\%). In Chile, there are no previous studies reporting the prevalence of dental anxiety in paediatric populations. The available data from other countries report the percentage of DA to range from $13.6 \%$ to $38 \%$ (Nicolas et al., 2010; Carrillo-Diaz et al., 2012).

The low frequency of DA in our sample may have several explanations. The first is that, although this scale is widely used in research with good reliability, the instrument used (FIS) was not properly interpreted by children (Buchanan \& Niven, 2003). The difficulty may be associated with the tendency to choose the options that are more pleasing (smiley faces), which could be a bias that may affect the validity of the tool. Nevertheless, the results of the simultaneous Frankl scale application are in agreement with the FIS results. Therefore, it is doubtful that the low frequency of DA in the study sample is explained by an issue of the validity and reliability of the instrument.

The second explanation could be related to special characteristics of the sample population of children. The health centres in this study serve a population assigned territorially, so there is a close relationship between the oral health team and patients. This situation could enhance a psychological situation of greater control and, therefore, more security due to a familiar environment, which gives the perception of controllability and predictability. In this case, the type of relationship established between the oral health team and patients could explain the low frequency of DA in this sample.

A third reason for the low DA frequency may be related to the low frequency of emergency pain present in the study group (11.6\%). Most of the children did not have dental pain at the time of admission to the programme. Studies show that children who receive dental care related to invasive dental procedures experience increased anxiety (Ten Berge et al., 2002; Olak et al., 2013; Gao et al., 2013), and on the other hand, when the treatment is not related to dental pain, they show low levels of dental anxiety (Ramos-Jorge et al., 2013). In this study, most of the interventions were planned and thus were developed under "painless" conditions. 
The low frequency of moderate / high DA hinders the possibility to evaluate the impact of MD. Most likely, this technique operates effectively in children who experience moderate or high levels of DA (Lahmann et al.). However, it is difficult to assess MD in a group that has a low level of DA because it is not expected that the intervention would significantly reduce DA when it is already low. Unfortunately, in this study, it was not possible to assess MD only in children with high DA because this group comprised very few individuals.

Although some studies show that dental treatment could cause DA, especially when it is traumatic (Smith \& Freeman, 2010), in this study, the dental treatment was a neutral experience that did not promote the development of DA. Most of the children received restorative treatment $(69.6 \%)$ that, in fact, is a less traumatizing experience. Scheduled dental care not related to the treatment of acute pain is a good opportunity for behavioural management sessions that allow a progressive approach to the aversive stimulus and is therefore experienced with more controllability by the child.

There was no impact of MD on adherence to treatment because there was no reduction in DA between the groups with MD compared to the group without MD. Despite this, we can affirm that the overall adherence to treatment was poor. The first indicator is the attendance of dental check-ups. Only $47.7 \%$ of children attended at 6-month follow-up, and 37.5 $\%$ of the initial sample did not complete their dental treatment so that discharge was not possible. We do not know the reason for the treatment withdrawal, as evaluating it was not an aim of this study. However, we believe it is an important issue, and in the future, it may identify the reason that caregivers give for not attending dental check-up.

Other adherence indicators included clinical and laboratory indicators, and behavioral records. The presence of caries, $\mathrm{OHI}$ and $\mathrm{S}$. mutans count showed a significant decrease in the discharge time. However, at the 6-month follow-up, they decreased according to the records scores. Likewise, most patients incorporated good oral health behaviors at the time of discharge, but these behaviors suffered a setback at the follow-ups.

All of the indicators show that dental treatment adherence is poor. Apparently, the children did not incorporate the necessary behaviors to maintain good oral health. The abandonment of healthy behaviors is strongly related to poor clinical indicators, so we can assume that the rapid deterioration of the oral health after the integral discharge, can be attributed to the failure to incorporate these behaviors and not to technical problems in the treatments.

Adherence to treatment is a concept that highlights the active involvement and voluntary cooperation of the patient (Ortiz \& Ortiz, 2007), as well as the commitment and motivation of the oral health team. The variables related to the patient play an important role (Brawley \& Culos-Reed, 2000). However, in our study, it is difficult to assess these because although the instructions are given to children and caregivers, the caregivers are the decision-makers for motivating and determining the health behavior of the children.

The education level of caregivers could be associated with the low AT. Evidence shows that the AT is higher when subjects have a high educational level (Clark et al. 2012). Contrary to expectations, the majority of caregivers $(76.5 \%)$ had completed secondary education, so we could not attribute the low AT to a low educational level.

In summary, a low prevalence of DA and poor adherence to dental care were detected in the sample, as indicated by clinical, laboratory and behavioural measures. However, there is no information that can explain or suggest the cause of this relationship, so future studies in these areas are fundamental to a deeper understanding of the phenomenon, which may suggest behavioural strategies to improve the AT in 6-year-old children who are beneficiaries of the comprehensive oral health program of the Chilean government.

The current study has limitations, as are inherent in many long-term studies such as the drop out of the sample. The small sample of children who were assessed at 6-month appointments is a limitation of the study. Another limitation not considered in the sample size calculation was the expected proportion of children with low dental anxiety. Finally, the unblinded dentists may introduce a bias also; a lack of blinding may influence compliance with the intervention or the use of cointerventions, which were not controlled. The majority of the behavioral studies has this limitations because it is not possible to blind the team who treat the patient. 


\section{CONCLUSIONS}

1) Dental anxiety is a phenomenon well recognized in clinical practice, but there are few studies reporting the frequency in the population, especially in children who are at the starting-age for school, a key time for incorporating behaviors and habits. This study shows that the frequency of DA is not as high as expected, and the causes were discussed, emphasizing the close relationship between the oral health team and patients/ caregivers as a probable cause of the low prevalence of dental anxiety in moderate/severe levels.

2) There are few reports that examine adherence to dental treatment in children and their caregivers. This study shows that despite efforts by public health institutions, which offer free dental care and oral health education sessions, there is no decrease in the risk of caries development. The probable reasons for this situation are discussed, and possible lines of investigation into the matter are suggested.

\section{ACKNOWLEDGEMENTS}

This research project was funded by the National Fund for Health Research (FONIS, for its acronym in Spanish) under the National Commission for Scientific and Technological Research (CONICYT) and the Ministry of Health of Chile (MINSAL, its Spanish acronym). Project code: SA11I2025.

ROJAS-ALCAYAGA, G. A.; ALFARO, K.; RÍOS-ERAZO, M.; HERRERA, A. C. \& BARAHONA, P. Efectividad de la distracción musical sobre la ansiedad dental y adherencia a tratamiento en niños de 6 años: ensayo clínico aleatorizado. Int. J. Odontostomat., 12(1):35-42, 2018.

RESUMEN: La ansiedad dental puede ser una barrera para seguir conductas saludables. La distracción musical es una estrategia efectiva para reducir la ansiedad dental y mejorar la adherencia al tratamiento. El objetivo fue determinar el efecto de la distracción musical sobre la ansiedad dental y la adherencia al tratamiento en niños de 6 años. Ensayo multicéntrico de control aleatorizado con 176 niños asignados a dos grupos paralelos. Un grupo recibió atención dental habitual (n 88) y el otro estuvo expuesto a distracción musical durante el cuidado dental habitual (N 88). El resultado primario fue la ansiedad dental y secundaria fue el estado de salud oral y las conductas de salud oral. Ambos fueron evaluados al inicio, dados de alta y seguidos durante seis meses. La ansiedad dental media / alta fue ex- hibida por $16,1 \%$ de los niños. La distracción musical no tuvo ningún efecto sobre los niveles de ansiedad dental en el grupo experimental en comparación con el grupo control en ninguno de los momentos evaluados. El efecto del tamaño fue 0,35 y 0,15 (Cliff's Delta) para el inicio y el alta y 0,57 y 0,35 para el inicio y los seis meses de seguimiento. Solo el $47,7 \%$ de la muestra asistió a los 6 meses de seguimiento. La ansiedad dental no prevalece en la muestra y no se ve beneficiada por la distracción musical. Las acciones educativas del programa de atención dental no son suficientes para lograr cambios permanentes a largo plazo en el comportamiento de salud oral.

PALABRAS CLAVE: Distracción musical, ansiedad dental, cuidado dental para niños, cumplimiento del paciente

\section{REFERENCES}

Armfield, J. M.; Stewart, J. F. \& Spencer, A. J. The vicious cycle of dental fear: exploring the interplay between oral health, service utilization and dental fear. BMC Oral Health, 7:1, 2007.

Brawley, L. R. \& Culos-Reed, S. N. Studying adherence to therapeutic regimens: overview, theories, recommendations. Control Clin. Trials, 21(5 Suppl.):156S-63S, 2000.

Buchanan, H. \& Niven, N. Self-report treatment techniques used by dentists to treat dentally anxious children: a preliminary investigation. Int. J. Paediatr. Dent., 13(1):9-12, 2003.

Buchanan, H. \& Niven, N. Validation of a Facial Image Scale to assess child dental anxiety. Int. J. Paedriatr. Dent., 12(1):47-52, 2002.

Carrillo-Díaz, M.; Crego, A.; Armfield, J. M. \& Romero-Maroto, M. Treatment experience, frequency of dental visits, and children's dental fear: a cognitive approach. Eur. J. Oral Sci., 120(1):7581, 2012.

Chhabra, N.; Chhabra, A. \& Walia, G. Prevalence of dental anxiety and fear among five to ten year old children: a behaviour based cross sectional study. Minerva Stomatol., 61(3):83-9, 2012.

Clark, N. M.; Ko, Y. A.; Gong, Z. M. \& Johnson, T. R. Outcomes associated with a negotiated asthma treatment plan. Chron. Respir. Dis., 9(3):175-82, 2012.

de Carvalho, R. W.; de Carvalho Bezerra Falcão, P. G.; de Luna Campos, G. J.; de Souza Andrade, E. S.; do Egito Vasconcelos, B. C. \& da Silva Pereira, M. A. Prevalence and predictive factors of dental anxiety in Brazilian adolescents. J. Dent. Child. (Chic.), 80(1):41-6, 2013.

Edelstein, B. L. \& Chinn, C. H. Update on disparities in oral health and access to dental care for America's children. Acad. Pediatr., 9(6):415-9, 2009.

Edelstein, B. L. Disparities in oral health and access to care: findings of national surveys. Ambul. Pediatr., 2(2 Suppl.):141-7, 2002.

Eitner, S.; Wichmann, M.; Paulsen, A. \& Holst, S. Dental anxiety--an epidemiological study on its clinical correlation and effects on oral health. J. Oral Rehabil., 33(8):588-93, 2006.

Frankl, S. N.; Shiere, F. R. \& Fogels, H. R. Should the parents remain with the child in the dental operatory? J. Dent. Child., 29:150-63, 1962.

Gao, X.; Lo, E. C.; McGrath, C. \& Ho, S. M. Innovative interventions to promote positive dental health behaviors and prevent dental caries in preschool children: study protocol for a randomized controlled trial. Trials, 14:118, 2013. 
ROJAS-ALCAYAGA, G. A.; ALFARO, K.; RÍOS-ERAZO, M.; HERRERA, A. C. \& BARAHONA, P. Music distraction effectiveness in dental anxiety and treatment adherence in 6year-old children: A randomized clinical trial. Int. J. Odontostomat., 12(1):35-42, 2018.

Goettems, M. L.; Ardenghi, T. M.; Demarco, F. F.; Romano, A. R. \& Torriani, D. D. Children's use of dental services: influence of maternal dental anxiety, attendance pattern, and perception of children's quality of life. Community Dent. Oral Epidemiol., 40(5):451-8, 2012.

Klassen, J. A.; Liang, Y.; Tjosvold, L.; Klassen, T. P. \& Hartling, L. Music for pain and anxiety in children undergoing medical procedures: a systematic review of randomized controlled trials. Ambul. Pediatr., 8(2):117-28, 2008.

Lahmann, C.; Schoen, R.; Henningsen, P.; Ronel, J.; Muelhbacher, M.; Loew, T.; Tritt, K.; Nickel, M. \& Doering, S. Brief relaxation versus music distraction in the treatment of dental anxiety: a randomized controlled clinical trial. J. Am. Dent. Assoc., 139(3):317-24, 2008.

Marwah, N.; Prabhakar, A. \& Raju, O. S. Music distraction--its efficacy in management of anxious pediatric dental patients. J. Indian Soc. Pedod. Prev. Dent., 23(4):168-70, 2005.

Milsom, K. M.; Tickle, M.; Humphris, G. M. \& Blinkhorn, A. S. The relationship between anxiety and dental treatment experience in 5-year-old children. Br. Dent. J., 194(9):503-6, 2003.

Nicolas, E.; Bessadet, M.; Collado, V.; Carrasco, P.; Rogerleroi, V. \& Hennequin, M. Factors affecting dental fear in French children aged 5-12 years. Int. J. Paediatr. Dent., 20(5):366-73, 2010.

Olak, J.; Saag, M.; Honkala, S.; Nõmmela, R.; Runnel, R.; Honkala, E. \& Karjalainen, S. Children's dental fear in relation to dental health and parental dental fear. Stomatologija, 15(1):26-31, 2013.

Ortiz, M. P. \& Ortiz, E. P. Health psychology: a key to understand therapeutic adherence. Rev. Med. Chil., 135(5):647-52, 2007.

Piovano, S.; Squassi, A. \& Bordoni, N. E. Estado del arte de indicadores para la medición de caries dental. Rev. Fac. Odontol. (B. Aires), 25(58):29-43, 2010.

Ramos-Jorge, J.; Marques, L. S.; Homem, M. A.; Paiva, S. M.; Ferreira, M. C.; Oliveira Ferreira, F. \& Ramos-Jorge, M. L. Degree of dental anxiety in children with and without toothache: prospective assessment. Int. J. Paediatr. Dent., 23(2):125-30, 2013.

Sanikop, S. Agrawal, P. \& Patil, S. Relationship between dental anxiety and pain perception during scaling. J. Oral Sci., 53(3):3418, 2011.

Sheiham, A. Oral health, general health and quality of life. Bull. World Health Organ., 83(9):644, 2005.

Smith, P. A. \& Freeman, R. Remembering and repeating childhood dental treatment experiences: parents, their children, and barriers to dental care. Int. J. Paediatr. Dent., 20(1):50-8, 2010.

Ten Berge, M.; Veerkamp, J. \& Hoogstraten, J. The etiology of childhood dental fear: the role of dental and conditioning experiences. J. Anxiety Disord., 16(3):321-9, 2002.
Corresponding author:

Andrea Herrera Ronda

Behavioral Sciences Area

Institute for Research in Dental Science

Dental School

Universidad de Chile

Santiago

CHILE

Email: aherrera@odontologia.uchile.cl

Received: 26-07-2017

Accepted: 07-12-2017 